\title{
EL NOMBRE DE UN PROBLEMA. ALAIN BADIOU, SLAVOJ ŽIŽEK Y LA ACTUALIDAD DEL COMUNISMO
}

\author{
Santiago M. Roggerone ${ }^{1}$ \\ Universidad de Buenos Aires
}

http://dx.doi.org/10.5209/rev_NOMA.2015.v45.n1.51336

\begin{abstract}
Resumen: En el presente artículo se indaga en las nuevas perspectivas sobre el comunismo. Básicamente, el objetivo trazado consiste en explorar la actualidad teórico-política del mismo. Si bien se concede la mayor atención a las obras de Alain Badiou y Slavoj Žižek, se atiende también a lo argumentado por otros autores contemporáneos. En un primer momento se discute en torno a la diferencia entre comunismo y socialismo. Hecho esto, se pasa a reconstruir la concepción badiousiana sobre la Idea y la hipótesis comunistas. Luego se expone cómo el trabajo de Žižek se engarza con los planteos de Badiou y se presenta las críticas y consecuentes modificaciones que aquél efectúa a éste. Finalmente, tras realizar un sucinto excurso sobre el arte y las utópicas señales del futuro contenidas en él, a modo de conclusión se despliega la intuición que en todo momento acompaña al artículo: antes que una solución de las preguntas hoy acuciantes, el comunismo representa el nombre de un problema sobre el que hay que pensar una y otra vez.
\end{abstract}

Palabras clave: Comunismo; Badiou; Žižek.

\section{The Name of a Problem. Alain Badiou, Slavoj Žižek and the Actuality of Communism}

\begin{abstract}
The present paper looks into the new perspectives on communism. Basically, its aim is to explore the theoretical and political actuality of the latter. It mainly attends to the works of Alain Badiou and Slavoj Žižek, but also deals with the ideas of other contemporary authors. Firstly, the paper discusses the difference between communism and socialism. After that, it reconstructs the Badiouian conception of the Idea and the hypothesis of communism. Later, it explains how Žižek's work links together with Badiou's arguments, and presents Žižek's main critiques and modifications. Finally, after a brief excursus on art and the utopian signs of the future included in it, the paper goes back to the intuition outlined at the beginning: communism is not an answer to nowadays questions; it represents the name of a problem that has to be thought over and over again.
\end{abstract}

Keywords: Communism; Badiou; Žižek.

Recientemente, el filósofo Slavoj Žižek ha señalado que antes que una solución a los problemas que afrontamos, el comunismo evoca hoy "el nombre de un problema" - esto es, "una tarea para la cual no hay a mano una fórmula rápida" (Žižek, 2011b: 150). Vale decir, el problema al que nos enfrentamos cuando hablamos de comunismo sería "el problema de lo común en todas sus dimensiones" (Žižek, 2012a: 489):

\footnotetext{
${ }^{1}$ Es Licenciado y Profesor en Enseñanza Secundaria, Normal y Especial en Sociología por la Universidad de Buenos Aires (UBA), así como Doctorando en Ciencias Sociales por la misma Universidad. Cursó la Maestría en Sociología de la Cultura y el Análisis Cultural en el Instituto de Altos Estudios Sociales perteneciente a la Universidad Nacional de San Martín, habiendo entregado ya su Tesis y encontrándose a la espera de defenderla. Dispone de una Beca Interna Doctoral otorgada por el Consejo Nacional de Investigaciones Científicas y Técnicas con sede de trabajo en el Instituto de Investigaciones Gino Germani (UBA) y se desempeña como auxiliar docente en la Carrera de Sociología de la Facultad de Ciencias Sociales (UBA). E-mail de contacto: santiagoroggerone@gmail.com
} 
lo común de la naturaleza como la sustancia de nuestra vida, el problema de nuestra biogenética común, el problema de lo común cultural ("la propiedad intelectual"), y por último, pero no menos importante, el problema de lo común como el espacio universal de la humanidad del que nadie debería quedar excluido. Cualquiera que pueda ser la solución, tendrá que resolver este problema (ídem).

Abordado justamente como una pregunta antes que como una respuesta, en los últimos años el comunismo ha sido objeto de una significativa renovación. ¿Pero por qué el comunismo? ¿A qué responde que aquello reconsiderado actualmente sea el comunismo? A decir verdad, la situación es en parte la opuesta a la que se experimentaba hace unos veinte años, cuando desde las usinas ideológicas del neoliberalismo se clamaba la muerte de las ideologías y el historiador François Furet (1995) podía archivar para siempre la cuestión - "inmovilizado en su eternidad mercantil, el capitalismo pasaba a ser el horizonte insuperable de todos los tiempos!" (Bensaïd, 2003: 10), escribe Daniel Bensaïd rememorando lo que acontecía por entonces. En aquel tiempo, hasta los propios marxistas reconocían abiertamente que el proyecto comunista había fracasado y que la única esperanza que quedaba era la del socialismo.

Ahora bien, es claro que ninguna de las "palabras de la emancipación" ha conseguido salir indemne de las "tormentas del siglo pasado" (Bensaïd, 2010: 10).

Se puede decir de ellas, como de los animales de la fábula, que no han quedado todas muertas, pero todas han sido gravemente heridas. Socialismo, revolución, anarquía incluso, no están mucho mejor que comunismo. El socialismo se ha implicado en el asesinato de Karl Liebknecht y Rosa Luxemburg, en las guerras coloniales y las colaboraciones gubernamentales hasta el punto de perder todo contenido a medida que ganaba en extensión. Una metódica campaña ideológica ha logrado identificar a ojos de muchos la revolución con la violencia y el terror (ídem).

Sin embargo, "de todas las palabras ayer portadoras de grandes promesas y de sueños de porvenir, la de comunismo ha sido la que más daños ha sufrido debido a su captura por la razón burocrática de Estado y de su sometimiento a una empresa totalitaria" (ídem). ¿A qué obedecería, entonces, la necesidad de reparar la palabra y ponerla nuevamente en movimiento? ¿Por qué el interés en un significante añejo —anacrónico si se quiere-como el de comunismo, por parte de aquellas perspectivas que actualmente irrumpen en la escena intelectual y el teatro de la política emancipatorio-radical contemporánea?

En lo que sigue intentaremos explorar estos interrogantes. Para ello daremos cuenta de los principales argumentos teórico-políticos que son desplegados por las nuevas perspectivas sobre el comunismo. Aunque el centro de nuestra atención estará puesto en el trabajo de Alain Badiou y sobre todo en el de Žižek sin lugar a dudas, los pensadores que más se han esforzado por poner en pie las perspectivas mencionadas-, a lo largo de estas páginas atenderemos también a 
lo que ha sido desarrollado recientemente por autores como Antonio Negri, Jacques Rancière o Fredric Jameson. Esperamos que al finalizar la exposición el lector disponga de los elementos indispensables para meditar sobre la actualidad del comunismo.

Durante muchísimo tiempo la izquierda ha tenido la convicción de que, a diferencia del comunismo, el socialismo es posible. En definitiva, desde finales del siglo XIX existe algo llamado socialdemocracia cuya raison d'être se relaciona con la idea de que el comunismo es una quimera. Pero en los últimos años esta lectura ha comenzado a perder adeptos. En efecto, en el contexto de la crisis del capitalismo desatada en 2008, la izquierda empezó a abandonar la posición notoriamente melancólica y fatalista a la que, en su intención purista-especulativa de hacer completa tabla rasa, hasta el momento se aferraba con uñas y dientes. Con ello ha dado inicio a un lento pero firme proceso de resurrección del comunismo.

Hoy en día "el comunismo está otra vez a las puertas" (Žižek, 2011b: 98). La despolitización y la retórica pseudo-política de la indignación moral parecerían estar perdiendo cada vez mayor terreno; el sobreviviente y la víctima dan paso al luchador y el militante. Los antiguos izquierdistas anticomunistas vuelven sobre sus pasos -es "como si, después de de una vida de traición depravada", buscasen "morir reconciliados con la Idea comunista" (ibídem: 180). Tal como recientemente evidenciaron las protestas y disturbios que sacudieron al mundo, la voluntad, el deseo y la organización colectiva vuelven a la palestra. El panorama ha cambiado tanto que alguien como Álvaro García Linera puede plantear que "el horizonte general de nuestra época es comunista" (García Linera, 2008: 75). ${ }^{2}$

A entender de Jodi Dean, la idea de horizonte con la que juega el actual Vicepresidente del Estado Plurinacional de Bolivia, no indica un

futuro perdido sino una dimensión de la experiencia que no podemos perder jamás, incluso si no podemos verla, como cuando estamos perdidos en la neblina o no hacemos más que mirar nuestros pies. El horizonte es real en el sentido de imposible —nunca podemos alcanzarlo- y en el sentido de actual (la noción de lo Real de Jacques Lacan connota ambas cosas). El horizonte moldea nuestro contexto. Podemos perder el rumbo, pero el

\footnotetext{
${ }^{2}$ Este comunismo, añade García Linera, "se tendrá que construir a partir de capacidades autoorganizativas de la sociedad, de procesos de generación y distribución de riqueza comunitaria, de autogestión. Pero en este momento está claro que no es un horizonte inmediato, el cual se centra en la conquista de igualdad, redistribución de riqueza, ampliación de derechos. La igualdad es fundamental porque quiebra una cadena de cinco siglos de desigualdad estructural, ese es el objetivo de la época, hasta donde puede llegar la fuerza social, no porque lo prescribamos así, sino porque lo vemos. Más bien entramos a ver al movimiento con ojos expectantes y deseosos del horizonte comunista, pero fuimos serios y objetivos, en el sentido social del término, al señalar los límites del movimiento. $Y$ ahí viene la pelea con varios de los compañeros acerca de qué cosa era posible hacer" (García Linera, 2008: 75).
} 
horizonte es una dimensión necesaria de nuestra actualidad. Sea como el efecto de una singularidad o como el encuentro entre tierra y cielo, el horizonte es la división fundamental que establece quiénes somos (Dean, 2012: 1-2).

El problema habría estribado en que, a diferencia de la derecha, la izquierda perdió de vista este horizonte —ciertamente, la derecha mantiene todavía al comunismo "dentro de su campo de visión", concibiéndolo, más de veinte años después del désastre obscur que ocasionó su muerte, "como una amenaza" (ibídem: 6). Existirían buenas razones para que los conservadores, los liberales y hasta los demócratas se encuentren angustiados, pues "durante la última década, el comunismo habría retornado y revitalizado a la izquierda"; nuevamente, éste estaría remitiendo a "un discurso y un vocabulario que expresan los ideales universalistas, igualitarios y revolucionarios" (ibídem: 8).

Un indicador de este nuevo entusiasmo que despierta el comunismo entre la izquierda es el éxito del que han gozado las cuatro conferencias organizadas por Badiou y Žižek, donde intelectuales de todo el mundo, buscando repensar las coordenadas de la política radical e interrogando la posibilidad de una sociedad emancipada donde pueda vivirse en común, se han preguntado si el comunismo aún designa un nombre y un proyecto a los que vale la pena seguir guardando fidelidad. "La larga noche de la izquierda está llegando a su fin", escriben Douzinas y Žižek en la introducción al libro que recoge las ponencias presentadas en la primera de las conferencias en cuestión; "la derrota, las denuncias y la desesperación de las décadas de 1980 y 1990, el 'fin de la historia' triunfante, el mundo unipolar de la hegemonía estadounidense —rápidamente, todo esto se ha convertido en noticias viejas" (Douzinas y Žižek, 2010: VII).

Pero nuevamente, ¿qué es el comunismo? ¿Por qué otra vez el interés por él? Mejor dicho, ¿qué puede representar el comunismo hoy para nosotros? Para plantearlo con Bruno Bosteels, ¿cuál es la actualidad del comunismo? ¿Puede evocar éste algo más que una "ética pura del coraje y el compromiso —la ética de no ceder al propio deseo o a la fidelidad por el comunismo como Idea?" (Bosteels, 2011: 16). En otras palabras, ¿puede el comunismo constituir algo más que "una reliquia del pasado", un "objeto de reminiscencias nostálgicas o incriminatorias"?; ¿puede ser "algo más que una utopía de almas bellas" (ibídem: 19)?

\footnotetext{
${ }^{3}$ Coordinada por Costas Douzinas, Badiou y Žižek, la primer conferencia fue celebrada en marzo de 2009 en la Birbeck School of Law de Londres; bajo el título de Sobre la idea del comunismo, las ponencias presentadas aparecen compiladas al año siguiente; cfr. Hounie (2010). La segunda conferencia, Idee des Kommunismus. Philosophie und Kunst, se realizó en junio de 2010 en Volksbühne am Rosa-Luxemburg-Platz (Berlín); en 2010, Badiou y Žižek (2010) publicaron en francés las intervenciones que tuvieron lugar en el encuentro. La tercer conferencia, Communism, a New Beginning?, tuvo lugar en octubre de 2011 en la ciudad de Nueva York (más precisamente, en The Cooper Union for the Advancement of Science and Art); en 2013, las ponencias del simposio aparecieron editadas a instancias de Žižek (2014). Entre septiembre y octubre de 2013, se celebra un cuarto evento en Seúl; bajo el título de The 4th Idea of Communism Conference, el mismo transcurre en la Kyung He University.
} 
¿En qué medida podemos decir que el comunismo hoy día todavía posee cierta actualidad, no sólo como un espectro sino como un movimiento real; no sólo como un espíritu que nos visita del pasado muerto sino como una alternativa a la izquierda melancólica? ¿Puede el comunismo ayudarnos a salir de la moralización de la política que es uno de los resultados más patentes de las interminables autoflagelaciones de la izquierda? ¿O, al contrario, debemos concluir que la invocación de la hipótesis comunista [...], sobre todo cuando está desvinculada de cualquier movimiento para abolir el estado actual de las cosas, es parte integral de la vieja genealogía de la moral con sus almas bellas y sus quietismos radicales? (Bosteels, 2013: 82).

A entender de Dean, sólo puede responderse a este tipo de interrogantes — detrás de los que se encontraría el Derrida de Espectros de Marx, claro está- con un enfático sí. Según la autora, el comunismo sería actual, continuaría revistiendo importancia puesto que aludiría, entre otras cosas, a "la soberanía del pueblo" vale decir, a la soberanía no de "una totalidad o una unidad", sino a la soberanía del "resto de nosotros, aquellos de nosotros cuyo trabajo, vida y futuro es objeto de expropiación, monetización y especulación para el goce económico de unos pocos" (ibídem: 69). Son dos, por lo tanto, los puntos que vale la pena defender: 1) "el deseo comunista designa la subjetivación de la grieta necesaria para la política, la división dentro del pueblo"; 2) "dicha subjetivación es colectiva" (ibídem: 179).

Si conceptualizamos la actualidad del comunismo de este modo, no queda más que desconfiar del futuro del socialismo: él ya no vendría a representar la "infame fase 'inferior' del comunismo", sino algo así como "su verdadero competidor, su mayor amenaza" (Žižek, 2011b: 112). Ésta es la tesis defendida por Negri en Goodbye Mr. Socialism; a propósito de la misma, Michael Hardt anota:

Con demasiada frecuencia parecería que nuestras únicas opciones son el capitalismo o el socialismo, la regla de la propiedad privada o la de la propiedad pública, de modo tal que la única cura para los males del capital es hacerlo público, esto es, ejercer la regulación estatal. Pero tenemos que explorar otra posibilidad: ni la propiedad privada del capitalismo ni la propiedad pública del socialismo, sino lo común en el comunismo (Hardt, 2010: 129). ${ }^{4}$

Según esta tesis, en el contexto histórico del fracaso del socialismo realmente existente y la bancarrota del capitalismo, lo único que habría de quedarnos como opción sería el comunismo -éste aún poseería actualidad y potencial emancipatorio-radical, no a pesar sino a causa de la perversión estalinista. Esta hipótesis gana sustento si se advierte que el capitalismo tiende cada vez más a estrechar lazos con el socialismo:

\footnotetext{
${ }^{4}$ A entender de Negri, "el comunismo es el enemigo del socialismo porque el socialismo es la forma clásica de este segundo modelo de alienación de la potencia proletaria, que también exige una organización deformada de la producción de su subjetividad. Las perversiones del 'socialismo real' han neutralizado un siglo de lucha de clases y han disipado todas las ilusiones de la filosofía de la historia" (Negri, 2010: 159).
} 
La única manera que tiene el sistema capitalista global de sobrevivir a su antagonismo a largo plazo y evitar simultáneamente la solución comunista será reinventar alguna clase de socialismo, en forma de comunitarismo, populismo, capitalismo con valores asiáticos, o alguna otra configuración. Por ello, el futuro será comunista... o socialista (Žižek, 2011b: 111).

Los salvamentos del sistema financiero que tuvieron lugar en años recientes bajo el pretexto de estabilizar la economía global, dan cuenta del nuevo vínculo entre capitalismo y socialismo. En el horizonte despejado a partir de 2008 se encontraría la China contemporánea -esto es, el capitalismo con valores asiáticos à la China. En síntesis, la crisis habría marcado el comienzo de una "forma autoritaria de capitalismo" (ibídem: 152) —de un capitalismo socialista, de un socialismo para ricos en donde se privilegia lo privado a expensas de lo común como quizás nunca antes se lo hizo - con el que se pone punto final al sueño del Estado de bienestar $y$ al romance con la democracia y el liberalismo.

Pero el nuevo comunismo que en este contexto tanta simpatía despierta entre los izquierdistas no sólo ya no tiene nada que ver con el socialismo, sino tampoco con el marxismo - circunstancia que, a decir verdad, ha despertado todo tipo de polémicas. ${ }^{5}$ Es cierto que temporalmente el comunismo precede al marxismo. Sería necio negar que existieron (y aún existen) formas de comunismo utópicolibertarias - formas primitivas y comunitarias, precoloniales y poscoloniales- que fueron (y son) pre-marxistas, no-marxistas o incluso anti-marxistas. Como bien indica Jean-Luc Nancy (2010), la existencia de la palabra se remonta al siglo XIV, su uso escrito (a través de Victor d'Hupay de Fuveau) al XVIII y su aplicación política (a través de Gracchus Babeuf) a los años inmediatamente posteriores a la Revolución Francesa. ${ }^{6}$ No obstante, resulta harto complicado desligar el término de las propiedades atribuidas por Marx. A fin de cuentas, es él quien en los Manuscritos económico-filosóficos de 1844 le concede por primera vez el estatuto de un "naturalismo consumado" (Marx, 2004: 144), de "la verdadera solución del

\footnotetext{
${ }^{5}$ Esto es lo que puede inferirse de los lineamientos principales de las ponencias presentadas en la contra-conferencia Puissances du communisme (De quoi communisme est-il aujourd'hui le nom?), realizada en París en enero de 2010 y organizada por la Societé Louise Michel y la Université Paris-VII —el evento se celebró homenajeando a Bensaïd, quien, tras batallar con una larga enfermedad, falleció diez días antes de que el mismo se suscitara (estaba proyectado que el autor participara de la mesa de cierre de la conferencia, Des communistes sans communisme?, junto a Rancière y Žižek). Algo similar se desprende de los planteos realizados en el debate The Idea of Communism, organizado por el Socialist Workers Party británico en el marco del festival Marxism 2010 y celebrado en el mes de julio en Bloomsbury, Londres. Si bien no hay publicaciones que recojan las intervenciones que tuvieron lugar en estos eventos, cabe destacar la existencia de la encuesta De quoi "communisme" est-il le nom? que, en calidad de preparación de la contraconferencia de enero de 2010 y en alusión directa al ensayo de Badiou ¿Qué representa el nombre de Sarkozy?, apareciera en la edición de invierno de 2009 de ContreTemps bajo la dirección de Bensaïd.

${ }^{6}$ En el siglo XVI, durante la Revolución Inglesa, la palabra también se hace presente a través de la expresión Commonwealth. Asimismo, cabe señalar que el comunismo se encuentra inextricablemente unido a nombres como los de Espartaco, Thomas Müntzer, Maximilien Robespierre, François Toussaint-Louverture y, por supuesto, Louis Auguste Blanqui —habría que ver hasta qué punto el término se relaciona con figuras del socialismo utópico como Henri de SaintSimon, Charles Fourier y Robert Owen. Para una historia del comunismo, véase Martelli (2009).
} 
conflicto que el hombre sostiene con la naturaleza y con el propio hombre", de "la verdadera solución de la pugna entre existencia y esencia, entre objetivación y autoconfirmación, entre libertad y necesidad, entre individuo y género" —esto es, el estatuto de "la solución del enigma de la historia" (ibídem: 142). Posteriormente, ya en colaboración con Engels, lo caracterizaría no como "un estado que debe implantarse" o "un ideal al que haya de sujetarse la realidad", sino como "el movimiento real que anula y supera al estado de cosas actual" (Marx y Engels, 1985: 37) —es decir, no como algo muerto, fijo, fétido, putrefacto (un Estado o un estado de cosas, lo mismo da), sino como algo eminentemente vivo, en constante desarrollo, cuyas fuerzas se despliegan en la realidad material, afectándola, condicionándola y modificándola. Como sabemos, esta observación científica sería una de las piedras angulares del célebre Manifiesto redactado en 1848 y el principio rector de la Liga de los Comunistas y la Primera Internacional. ${ }^{7}$ Es sugerente, sin embargo, que Marx diese con un modelo para el comunismo, con una forma posible de comunismo — vale decir, con un "comunismo 'realizable"' (Marx, 1975: 43)—, recién en 1871, al calor de la irrupción del acontecimiento de la Commune de Paris. Asimismo, no deja de ser llamativo que la primera diferenciación entre socialismo y comunismo por él establecida se remonte a 1875 -recordemos que estos términos por mucho tiempo operaron como sinónimos-, año en el que escribe la Crítica del Programa de Gotha y acuña la expresión "dictadura revolucionaria del proletariado" (Marx, 1971: 38).

\section{II}

Si Negri es uno de los mayores responsables de que el comunismo no mantenga ya vínculo alguno con el socialismo, Badiou es el artífice principal de que aquél hoy se encuentre desligado del marxismo. Hacia el final de su ensayo de 2007 ¿Qué representa el nombre de Sarkozy?, el filósofo francés ofrece una presentación acabada de la tesis del quiebre entre comunismo y marxismo. ${ }^{8}$ No obstante, cabe aclarar que Badiou viene trabajando en esta tesis desde mayo de 1968, y en particular desde que la Gran Revolución Cultural Proletaria China terminara de fracasar —como enseguida veremos, mucho de lo sostenido actualmente por él ya había sido esbozado en De un desastre oscuro, escrito que se remonta a 1991 (es decir, al momento de la caída del Muro de Berlín y el estallido de la URSS).

\footnotetext{
7 "Las tesis teóricas de los comunistas [...] no son sino la expresión de conjunto de las condiciones reales de una lucha de clases existente, de un movimiento histórico que se está desarrollando ante nuestros ojos" (Marx y Engels, 2004: 39), escriben Marx y Engels en el Manifiesto.

${ }^{8}$ Antes de aparecer en este texto, la presentación en cuestión es esbozada por Badiou en el contexto de un seminario impartido en la École Normale Supérieure durante junio de 2007, como parte de las actividades desarrolladas por él en el Centre International d'Étude de la Philosophie Française Contemporaine. Introduciendo ligeras modificaciones, Badiou volvería a exponer su tesis en un artículo publicado a comienzos de 2008 en la New Left Review; cfr. Badiou (2008b). Aquí nos remitiremos exclusivamente a la esquematización argumental que es desplegada en ¿Qué representa el nombre de Sarkozy?
} 
Badiou parte de la intuición fundamental de que pese a todo el comunismo continúa siendo "la buena hipótesis" (Badiou, 2008a: 97). El autor no entiende al comunismo como "un programa", sino - y en esto parecería seguir a Kant- como "una Idea" que posee una "función [...] reguladora" (ibídem: 98). El comunismo no tiene ya nada que ver con el socialismo no sólo por lo que establecíamos antes con Negri, sino por el hecho mucho más importante de que, a diferencia del último, puede ser conceptualizado como una Idea. Se puede hablar de hipótesis comunista en tanto se reconozca la existencia de una Idea eterna del comunismo, dotada de una serie de invariantes o "invariables" (ibídem: 99) atemporales —esto quiere decir que los principios de la Idea podrían convocarse "sean cuales sean las declinaciones o variaciones que experimenten en contextos diferentes" (ibídem: 100). Básicamente, estas invariantes comunistas serían "la estricta justicia igualitaria, el terror disciplinario, el voluntarismo político y la confianza en el pueblo" - siguiendo a Badiou, Žižek se refiere a las mismas como "los "cuatro conceptos fundamentales' que actúan desde Platón, a través de las rebeliones milenarias medievales, del jacobinismo, el leninismo y el maoísmo" (Žižek, 2011b: 145).

A propósito de las invariantes en cuestión, vale la pena citar en extenso lo que Badiou apuntaba en 1991:

¿qué significa "comunista"? ¿Qué puede pensar la filosofía bajo este nombre (la filosofía bajo la condición de una política)? La pasión igualitaria, la Idea de justicia, la voluntad de romper con las componendas del servicio de los bienes, la deposición del egoísmo, la intolerancia a la opresión, el anhelo de cesación del Estado. La absoluta preeminencia de la presentación-múltiple sobre la representación. La tenaz obstinación militante, desencadenada por algún acontecimiento incalculable, de atribuir al azar el propósito de una singularidad sin predicado, de una infinidad sin determinación ni jerarquía inmanente, lo que yo llamo lo genérico, y que es - cuando su procedimiento es político- el concepto ontológico de la democracia, o del comunismo, da igual [...] La filosofía se da cuenta de que esta forma subjetiva acompaña desde siempre y para siempre a los grandes levantamientos populares cuando no son, precisamente, cautivos y opacos (como lo es todo lo que hoy se nos muestra: nacionalismo, fascinación mercantil, mafiosos y demagogos encarnados en el Parlamento), sino que están en ruptura libre con el ser-ensituación o con el ser-contado que los embrida. De Espartaco a Mao (no el Mao del Estado, que también existe, sino el Mao rebelde, extremo, complicado), de las sediciones democráticas griegas a la década mundial 1966-1976, es, en este sentido, cuestión de comunismo. Siempre será cuestión de comunismo, aun cuando la palabra, ensuciada, dé paso a alguna otra designación del concepto que ella recubre. Concepto filosófico, por lo tanto eterno, de la subjetividad rebelde. En 1975 llamé a esto "invariantes comunistas". Mantengo la expresión, contra la de "muerte del comunismo". Y mantengo que, en el momento en que un monstruoso avatar propiamente desastroso (jun "Estado del comunismo"!) se descompone, se trata de esto: de que todo acontecimiento político fundador de verdad 
expone al sujeto que él induce a la eternidad de lo igual. "Comunismo", al haber nombrado esta eternidad, no puede servir adecuadamente para nombrar una muerte (Badiou, 2006: 17-19).

En la primera de las cuatro conferencias ya aludidas - aquella que se celebrara en Londres durante marzo de 2009-, Badiou se explaya sobre la especificidad de la Idea del comunismo. A su entender, la operación llamada Idea del comunismo reposa en una mediación impura entre historia, política y subjetividad; en otras palabras, posee "un componente político, un componente histórico y un componente subjetivo" (Badiou, 2010a: 17). Según el pensador francés, Idea sería el nombre dado a "una totalización abstracta de tres elementos primitivos, un procedimiento de verdad, una pertenencia histórica y una subjetivación individual" (ibídem: 20) —la "definición formal" de una determina Idea, entonces, remitiría a la "subjetivación de la relación entre la singularidad de un procedimiento de verdad y una representación de la Historia" (ídem). ${ }^{9}$

Cuando hablamos de la Idea del comunismo, por lo tanto, hablamos de una verdad política - esto es, de un procedimiento político de verdad a través del que tiene lugar una práctica y un pensamiento de emancipación colectiva- que se inscribe históricamente —es decir, que se secuencia y fecha temporalmente- y que es subjetivizada, militada. Ya nos hemos referido en parte a la verdad política de la Idea del comunismo - a fin de cuentas, actualidad es otro modo de decir verdad. En un momento nos ocuparemos de su inscripción histórica; antes, sin embargo, vale la pena precisar algo sobre su componente subjetivo.

En lo fundamental, el componente subjetivo de una Idea aludiría a la capacidad de todo individuo, de todo animal humano, de todo sujeto, de decidir ser parte de un procedimiento de verdad política, de convertirse en militante de una determinada verdad —ciertamente, más que una decisión o conversión, se trata de una incorporación. A decir de Badiou,

es el momento en el que un individuo decreta que puede traspasar los límites (de egoísmo, de rivalidad, de finitud...) impuestos por la individualidad (o la animalidad, que es lo mismo). Y puede hacerlo por cuanto, sin dejar de ser el individuo que es, llega a ser, además, por incorporación, una parte actuante de un nuevo Sujeto. Llamo a esta decisión, esta voluntad, "subjetivación". De manera más general, una subjetivación es siempre el movimiento mediante el cual un individuo fija el lugar que ocupa una verdad en relación con su propia existencia vital y con el mundo en el cual se desarrolla esa existencia (ibídem: 19).

Pasemos a la parte histórica de la Idea del comunismo, que en cuanto tal poco es lo que tiene que ver con la historia propiamente dicha, con la Historia con mayúsculas, con "la historia del Estado" (ibídem: 24), que por definición no es otra

\footnotetext{
${ }^{9}$ Es de destacar que al definir la Idea de esta manera, Badiou se aleje de -o al menos ponga en crisis a- su definición kantiana anterior. Como bien indica Bosteels, "él ahora pule el borde kantiano de su argumentación previa, inclinándose por el hecho de que, en términos filosóficos, la condición exacta de la hipótesis comunista es necesariamente indecidible" (Bosteels, 2011: 35).
} 
que la historia del état des choses. Ciertamente, la Idea del comunismo es eterna, está conferida de invariantes atemporales, regresa siempre después de su muerte. Por lo tanto, aquello que sólo puede poseer historia es la hipótesis que se deriva de la existencia de la Idea. Según Badiou, "ha habido dos grandes secuencias de la hipótesis comunista: la de su puesta en marcha, su instalación; y la de su primera tentativa de realización" (Badiou, 2008a: 105). La primera de estas dos secuencias habría durado unos ochenta años, extendiéndose desde la Revolución Francesa hasta la Comuna de París; la segunda se habría separado de la anterior por una pausa de cincuenta años, prolongándose desde la Revolución Rusa hasta el final de la Revolución Cultural. Mientras que lo que se halló en juego en la primera secuencia fue "la existencia de un movimiento popular y obrero" que pudiera actuar en nombre de la hipótesis y "la idea genérica de revolución", en la segunda se lidió con "la victoria" y el problema de "la perduración" —ya no se trató de "formular y de experimentar la hipótesis comunista, sino de realizarla" (ibídem: 107). Dicho de otro modo, mientras que la primera secuencia tuvo lugar "bajo el signo de la formulación de la hipótesis comunista y de su realidad en tanto que movimiento", la segunda lo hizo "bajo el signo de su organización disciplinada y militarizada, de su victoria local y de su duración" (ibídem: 108).

Siempre siguiendo a Badiou, las verdaderas dificultades habrían comenzado a suscitarse tras el triunfo y la realización de la hipótesis. En particular, lo que habría sucedido es que la forma Partido-Estado se mostró inapropiada para la construcción de la dictadura del proletariado —es decir, para la construcción de "un Estado que organizase la transición hacia el no-Estado"; para la construcción de "un poder del no-poder", de "una forma dialéctica del debilitamiento del Estado" (ídem). Con todo, durante la segunda secuencia no se habría logrado "asegurar la perduración real y la transformación creadora de la hipótesis comunista" (ibídem: 109). Fue así entonces que "la forma moderna del Estado reaccionario, el capitaloparlamentarismo", consiguió de vuelta "imponerse en los espíritus, disfrazado de 'democracia"' (ibídem: 110). Al igual que tras el final de la primera secuencia, se dio paso a un interludio en donde se declaraba que la hipótesis comunista era "insostenible, incluso absurda y criminal", y se reivindicaba la necesidad de "renunciar a ella" (ídem).

Para Badiou resulta claro que lo que vendrá no podrá ya ser "la continuación de la segunda secuencia" (ibídem: 111).

El marxismo, el movimiento obrero, la democracia de masas, el leninismo, el Partido del proletariado, el Estado socialista, todas esas destacables invenciones del siglo $X X$ ya no nos resultan realmente útiles. En el orden de la teoría deben ser conocidas y meditadas. Pero en el orden de la política, se han vuelto impracticables. Éste es un primer punto esencial del que debemos ser conscientes: la segunda secuencia está clausurada y es inútil querer continuarla o restaurara (ídem).

Lo que a entender del autor se impone es el nacimiento de una nueva secuencia de la hipótesis comunista, en la que ésta deberá ser presentada de una manera diferente. De acuerdo con esto, el problema de la tercera secuencia no podrá ser 
ya "ni la existencia en movimiento de la hipótesis ni su victoria disciplinada al nivel de Estado" (ibídem: 112). En lo fundamental, el problema de la tercera secuencia de la hipótesis comunista girará en torno al "modo propio en el que el pensamiento, ordenado por la hipótesis, se presenta en las figuras de la acción" (ídem). De lo que se tratará es de dar con

una nueva relación de lo subjetivo y lo objetivo que no sea ni el movimiento multiforme agitado por la inteligencia de la multitud (como creen Negri y los altermundistas), ni el Partido renovado y democratizado (como creen los trotskistas y los maoístas fosilizados) (ídem).

En el siglo XIX, la hipótesis comunista habría sido presentada a través de la fórmula del movimiento obrero; en el XX, lo habría hecho a través de la del partido comunista. Sería inútil volver a cualquiera de ellas. Lo que el porvenir depararía para nosotros es una nueva fórmula de la hipótesis comunista.

Así las cosas -y puesto que, como en el siglo XIX, lo que hoy estaría en peligro serían las condiciones mismas de existencia de la hipótesis-, se impondría la tarea exaltante de "hacer existir la hipótesis comunista en un modo distinto al de la primera secuencia" (ídem), de "reinstalar la hipótesis en el campo ideológico y militante" (ibídem: 113). Efectivamente, hoy en día, mientras experimentamos el agotamiento de un intervalo reaccionario que separa a la segunda secuencia de una tercera que todavía no ha visto la luz,

La hipótesis comunista sigue siendo la buena hipótesis [...] Si esta hipótesis debe ser abandonada, no vale la pena hacer nada en el ámbito de la acción colectiva. Sin el horizonte del comunismo, sin esta Idea, nada en el devenir histórico y político es susceptible, por su naturaleza, de interesar al filósofo. Que cada cual se ocupe de sus asuntos y no hablemos más del tema. Démosle la razón al hombre de las ratas, como hacen algunos antiguos comunistas, ávidos de prebendas o desprovistos ya de toda valentía. Pero mantenerse en la Idea, en la existencia de la hipótesis, no quiere decir que su primera forma de representación, centrada en la propiedad y en el Estado, haya de ser mantenida tal cual. En realidad, lo que nos viene dado como tarea, digamos incluso como deber filosófico, es ayudar a que surja un nuevo modo de existencia de la hipótesis (ibídem: 112-113).

Que la hipótesis comunista continúe siendo una buena hipótesis, y por tanto que la tarea de la hora consista en hacerla existir de un modo distinto, significa que los fracasos que ella experimentó en el despliegue de sus secuencias históricas previas, no fueron absolutos sino más bien relativos. Vale decir, de que la hipótesis comunista haya fracasado al intentar realizarse no se desprende que debamos "abandonar la hipótesis misma y renunciar a todo el problema de la emancipación" (Badiou, 2010b: 6). A entender de Badiou, si hay algo que debería abandonarse, ello sólo podría ser las fórmulas a través de las que la hipótesis intentó realizarse en el pasado. De lo único que da cuenta la circunstancia de que haya tenido lugar el fracaso, por lo tanto, es del hecho de que no se escogió el camino correcto para "resolver el problema inicial" (ídem) —a condición de que 
una determinada hipótesis no sea descartada, tras la existencia de un fracaso no puede esconderse otra cosa que la paciente "historia de la verificación de la hipótesis" (ibídem: 7). ${ }^{10}$

"Toda derrota revolucionaria", escribe Badiou,

posee siempre una parte negativa (muertes, encarcelamientos, traiciones, perdidas de fuerza, fragmentación), la cual a menudo se torna bastante evidente en el momento, y una parte positiva, la cual usualmente toma un largo tiempo en emerger (el ajuste de cuentas táctico y estratégico, el cambio de modelos para la acción, la invención de nuevas formas de organización) (ibídem: 9).

Tras el acontecer de la derrota, de lo que se trataría entonces es de sacar las lecciones adecuadas y luchar por la emergencia positiva de lo nuevo. Según el filósofo francés, la hipótesis comunista viene de toparse con duros fracasos - para ponerlo en los términos empleados en Lógica de los mundos: el procedimiento de verdad del comunismo viene de haber lidiado incorrectamente con obstáculos inherentes a su mundo, con elecciones binarias que en diversos puntos se le presentaron. Como dice Badiou, "todo fracaso es una lección que, en última instancia, puede ser incorporada dentro de la universalidad positiva de la construcción de una verdad" (ibídem: 39). Para que la hipótesis comunista continúe siendo la hipótesis correcta, la hipótesis verdadera, habría por tanto que sacar las lecciones de los fracasos experimentados y batallar por que ella pueda existir sin todo aquello que, en el pasado, la condujo a fallar —el movimiento, el partido, etc.

Siguiendo a Bosteels, sin embargo, podría argumentarse que no es que el proyecto comunista "falló", sino más bien que "fue derrotado" (Bosteels, 2011: 274), que se lo hizo fracasar. Es en este sentido que la tesis trotskista de la degeneración burocrática de la revolución y el Estado obrero soviético sigue poseyendo actualidad. Como sugiere Bensaïd, que Badiou sitúe el comienzo de la bancarrota del marxismo -esto es, el comienzo de su inoperabilidad dentro del procedimiento de verdad comunista- en un año como el de 1967, cuando la Comuna de Shanghái es aplastada y se suscita un dramático viraje en la Revolución Cultural, habla de una negativa a entrar del todo en el balance histórico de las experiencias del maoísmo y el estalinismo — “iVergüenza a quienes dejaron de ser comunistas al dejar de ser estalinistas y que no fueron comunistas más que mientras fueron estalinistas!" (Bensaïd, 2010: 10).

El hecho de que se haya hecho fracasar al proyecto comunista (desde dentro y desde fuera, claro está) no da crédito a la tesis de una derrota histórica que

\footnotetext{
${ }^{10}$ Cabe señalar aquí que tras el razonamiento de Badiou no sólo se encuentran los principios del falsacionismo científico, sino también lo que Mao llamaba lógica del pueblo: "Luchar, fracasar, luchar de nuevo, fracasar de nuevo, volver a luchar, y así hasta la victoria: ésta es la lógica del pueblo, que tampoco marchará jamás en contra de ella. Esta es otra ley marxista. La revolución del pueblo ruso siguió esta ley, y la ha seguido también la revolución del pueblo chino" (Tse-Tung, 1976: 445).
} 
inhabilitó a éste para siempre. Perry Anderson apunta en Spectrum que "no es lo mismo ser derrotado que doblegado" (Anderson, 2008: 13). De ser así, seguir peleando por el comunismo constituiría una opción totalmente válida. En todo caso, lo que la circunstancia de que se haya hecho fracasar al comunismo hace es ofrecer testimonio de la despolitización que tiene lugar como corolario de la huída de la historia hacia el terreno de la ontología - vale decir, como consecuencia del "salto fuera" de ella y el echar a correr "hacia la afirmación de la eternidad o, al menos, de la disponibilidad transhistórica del comunismo como Idea invariante" (Bosteels, 2011: 275). Es cierto que gracias a Badiou el comunismo logra resistir el impulso historicista que —al igual que el "énfasis en la diferencia, el flujo y la multiplicidad" - forma "parte de la ideología del capitalismo tardío" (ibídem: 277). Definido como una Idea, el comunismo puede reconocer la existencia de un "núcleo eterno o ahistórico" (ibídem: 288) que le permite evitar el historicismo y relacionarse con la historia de otra manera. El problema es que, pese a que ello le permita ganar "en extensión ética o filosófica", lo conmina también a perder "en precisión política” (Bensaïd, 2010: 10).

La palabra y la cosa no pueden quedar fuera del tiempo de las pruebas históricas a las que han sido sometidos. El uso masivo del título "comunista" para designar el Estado liberal autoritario chino pesará mucho más durante largo tiempo, a los ojos de la gran mayoría, que los frágiles brotes teóricos y experimentales de una hipótesis comunista. La tentación de sustraerse a un inventario histórico crítico conduciría a reducir la idea comunista a "invariantes" atemporales, a hacer de ella un sinónimo de las ideas indeterminadas de justicia o de emancipación, y no la forma específica de la emancipación en la época de la dominación capitalista (ídem).

Llegados a este punto, la pregunta que vale la pena formularnos es la que hace poco se hiciera Emmanuel Barot: “¿Qué hacer [...] para que la Idea se reapropie de las masas -es decir, que estas masas se reapropien de ella, le hagan perder su mayúscula y que vuelva a ser una fuerza material?" (Barot, 2013: 39). ¿Qué hace falta para que el comunismo tome un nuevo curso revolucionario? Como escribe Bosteels en su intervención de la conferencia de Londres, lo que urge hoy es que el comunismo vuelva a "encontrar su inscripción en el cuerpo concreto o en la carne de un sujeto político" (Bosteels, 2010: 71).

\section{III}

A continuación examinaremos la posición de Žižek ante el resurgimiento del comunismo que, como hemos visto hasta aquí, viene de la mano a la renuncia al proyecto socialista y el abandono del horizonte del marxismo. Al hacerlo podremos observar que constituye toda una alternativa insistir en el comunismo como una Idea eterna e invariante - como un núcleo imposible-real anti-historicista- pero, al mismo tiempo, continuar relacionándose con la historia de tal manera que el peligro de la despolitización consiga ser eludido. 
La caracterización filo-kantiana del comunismo como Idea transhistórica se da de bruces con todo lo que se deriva de la definición marxista de éste como movimiento real que abole el estado de cosas existente. A propósito, Bensaïd apunta:

El comunismo no es una idea pura, ni un modelo doctrinario de sociedad. No es el nombre de un régimen estatal, ni el de un nuevo modo de producción. Es el de un movimiento que, de forma permanente, supera/suprime el orden establecido. Pero es también el objetivo que, surgido de este movimiento, le orienta y permite, contra políticas sin principios, acciones sin continuidad, improvisaciones de a diario, determinar lo que le acerca al objetivo y lo que le aleja de él. A este título, no es un conocimiento científico del objetivo y del camino, sino una hipótesis estratégica reguladora. Nombra, indisociablemente, el sueño irreductible de un mundo diferente, de justicia, de igualdad y de solidaridad; el movimiento permanente que apunta a derrocar el orden existente en la época del capitalismo; y la hipótesis que orienta este movimiento hacia un cambio radical de las relaciones de propiedad y de poder, a distancia de los acomodamientos con un mal menor que sería el camino más corto hacia lo peor (Bensaïd, 2010: 13).

A su manera, Žižek permanece fiel a la conceptualización del comunismo como Idea eterna contra la que Bensaïd discute. Al igual que Badiou, el esloveno se aparta del horizonte teórico del marxismo y desatiende las implicancias que posee el comunismo como hipótesis estratégica reguladora.

Es en la ponencia que Žižek presenta en la conferencia de Londres de 2009 donde se percibe de la manera más clara el seguimiento que hace a Badiou. El autor alude allí a un texto de Lenin -escrito en 1922, en el contexto del fin de la guerra civil y el lanzamiento de la llamada Nueva Política Económica- en el que se evoca la imagen de un alpinista que para continuar su ascensión se ve obligado a volver sobre sus pasos, descender y explorar otros caminos. Al revolucionario ruso esta imagen le resultaba de utilidad para reflexionar sobre el significado del retroceso:

Habría que tener seguramente por perecidos a los comunistas que imaginasen que se podría terminar sin errores, sin retrocesos, sin rehacer multitud de veces los que no se ha hecho hasta el fin o lo que se ha hecho mal, la "empresa" histórica universal de acabar de colocar los cimientos de la economía socialista (sobre todo en un país de pequeños campesinos). No han perecido (y lo más seguro es que no perezcan) los comunistas que no se permiten hacerse ilusiones, que no caen en el abatimiento, conservando la fuerza y agilidad del organismo para volver a "abordar desde el principio" la dificilísima tarea (Lenin, 1973: 108).

A entender de Žižek, con su volver a abordar desde el principio, Lenin no hablaría 
meramente de acelerar el progreso y fortificar lo que se ha logrado ya, sino precisamente de descender y regresar al punto de partida: uno debería "volver a empezar", no desde el lugar adonde logró ascender en el esfuerzo anterior, sino desde el principio. Para decirlo con las palabras de Kierkegaard, un proceso revolucionario no es un proceso gradual, sino un movimiento repetitivo, un movimiento que repite el comienzo una y otra vez... y este es exactamente el punto donde nos encontramos hoy, después del "oscuro desastre" de 1989 (Žižek, 2010: 232).

Como Badiou, Žižek cree entonces que la tarea que la actualidad prescribe no consiste en '"continuar construyendo sobre los cimientos' de la época revolucionaria del siglo XX (que se extendió desde 1917 hasta 1989)", sino en "'descender' hasta el punto de partida y elegir una senda diferente" (ídem).

El Lenin traído a colación sería el Lenin en "su mejor estilo beckettiano" (ídem). En otras palabras, sería éste un Lenin que poetiza el fracaso —un Lenin, para decirlo en los términos empleados por Marx en El dieciocho Brumario de Luis Bonaparte, que extrae la poesía no "del pasado, sino [...] del futuro" (Marx, 2003: 37). En definitiva, esta poetización del fracaso sería lo que permitiría tematizar la imperturbable subsistencia de una Idea comunista que

sobrevive a los fracasos de su realización como un espectro que regresa una y otra vez, en una incesante persistencia que Beckett recapitula del modo más efectivo en [...] Rumbo a peor: "Inténtalo de nuevo. Fracasa de nuevo. Fracasa mejor" (Žižek, 2010: 240).

La perseverancia del comunismo es aquello que para Žižek sustenta la tesis de que, ante todo, la naturaleza de éste equivale a la de una Idea platónica, eterna e invariante, transhistórica y por tanto verdadera, que explota de tiempo en tiempo. Ahora bien, el pensador oriundo de Liubliana es consciente de que la caracterización del comunismo como Idea — vale decir, como Idea utópica de otro mundo posible - no posee ya "un vínculo privilegiado [...] con un momento histórico singular" (Žižek, 2011b: 146) —ciertamente, ésta vendría a ser la cara negativa de una universalidad comunista que rebasa mundos históricos específicos y horizontes de sentido particulares. De allí que para él no sea suficiente "permanecer fiel a la Idea comunista": lo que la actualidad reclama para sí es situar a ésta "dentro de los antagonismos de la realidad histórica" que le conceden "urgencia práctica" (ibídem: 106). En otras palabras, frente a Badiou, que elabora la Idea del comunismo como una idea regulativa kantiana que no posee vínculos reales con la historia - a decir verdad, el despliegue badiousiano de la hipótesis comunista posee las características de una "Kritik der reinen Kommunismus" (Žižek, 2012a: 482)_, Žižek intenta repetir el pasaje de Kant a Hegel. En definitiva, la intención del autor consiste en concebir la Idea del comunismo

como una Idea en el sentido hegeliano, es decir, como una Idea que está en el proceso de su propia actualización [...] Lo que la noción de Idea como un producto de sí misma hace visible no es un proceso de autoengendramiento 
idealista, sino el hecho materialista de que una Idea existe solo en, y a través de, la actividad de los individuos comprometidos con ella y motivados por ella (ídem).

La contracara de concebir al comunismo como Idea eterna sería advertir "que la situación que lo genera es igualmente eterna, es decir, que el antagonismo contra el que reacciona el comunismo siempre existirá" (Žižek, 2011b: 103). Esto no significa, sin embargo, que para ser fieles a la Idea comunista debamos transformar la crítica del capitalismo en una crítica de la razón instrumental o de la civilización tecnológica. Para ponerlo en los términos de Bosteels: "El comunismo como el movimiento real o actual que destruye el estado corriente de las cosas [...] no consiste en algún sueño idealista-especulativo sino que está vinculado de forma propiamente materialista, dialéctica, con las tendencias y contrafinalidades inherentes al capitalismo" (Bosteels, 2013: 89).

El problema continúa siendo entonces el capitalismo. Frente a Badiou, Žižek opina que "una revitalización de la 'crítica de la economía política' es el sine qua non de la política comunista contemporánea" (Žižek, 2012a: 197). Habría que ver realmente hasta qué punto la fórmula Partido-Estado constituyó "la característica definitoria del comunismo del siglo XX" — de por sí, el partido supone ya una "distancia respecto al Estado", "su organización representa una falta de confianza fundamental en los órganos y mecanismos" (ibídem: 453) de éste. Pero dudar de ello no le impide a Žižek considerar que, en el capitalismo contemporáneo capitalismo éste que, Badiou mediante, podríamos designar como un capitalismo falto de mundo_- el enemigo no es ya el Estado, sino más bien "un flujo de permanente autorrevolucionamiento" (Žižek, 2011b: 150) del que el mismo depende. En este contexto, ni el gradualismo reformista (la democracia radical/ el populismo à la Laclau) ni el autonomismo (la política de la sustracción à la Badiou) pueden ya constituir alternativas válidas:

En vez de tomar distancia respecto del Estado, la verdadera tarea debe ser hacer que el Estado funcione de modo no estatal. La alternativa "o bien la lucha por el poder del Estado (que nos convierte en lo mismo que el enemigo al que combatimos), o bien resistir retirándose a una posición de distancia respecto del Estado" es falsa; en sus términos, ambos comparten la misma premisa: la forma-Estado, en la manera que la conocemos actualmente, está aquí para quedarse, de modo que todo lo que podemos hacer es o bien apoderarnos del Estado o tomar una distancia respecto de él. Aquí, hay que repetir descaradamente la lección de Lenin en El Estado y la Revolución: el objetivo de la violencia revolucionaria no es apoderarse del Estado, sino transformarlo, cambiar radicalmente su funcionamiento, su relación con su base, etc. (ibídem: 151).

La izquierda debe deshacerse de una buena vez de sus fantasías de una democracia inmediata y transparente. Según Žižek, es aquí donde se encontraría el componente clave de la "dictadura del proletariado" (ídem). Para el esloveno, Badiou lleva la razón cuando escribe que hoy "el enemigo no se llama Imperio o Capital" sino más bien "Democracia" (Badiou, 2002: 14). Žižek entiende que "la 
aceptación de los mecanismos democráticos como el único marco para cualquier cambio posible [...] impide cualquier transformación radical de las relaciones capitalistas" (Žižek, 2012a: 459). Y la desfechitización de la democracia lo lleva a la desfechitización de la violencia — "el problema con el comunismo del siglo XX no fue su recurso a la violencia per se, sino el modo de funcionamiento que hizo inevitable ese recurso a la violencia" (ibídem: 461). Dictadura del proletariado, entonces, como una buena forma de violencia mediante la que puede hacerse aquello que resulta imposible cuando se permanece dentro del marco de la democracia - que en cuanto tal, en cuanto marco de la democracia realmente existente, es el marco del liberalismo parlamentario-: "utilizar al Estado como un instrumento, pero desde fuera" (ídem).

El comunismo resurge con ímpetu en nuestros días no sólo gracias a los esfuerzos filosóficos de Badiou, sino también debido al actual redescubrimiento de lo común que es privatizado "a expensas de la proletarización de la mayoría" (Žižek, 2011b: 111). En lo que a este redescubrimiento concierne, la referencia teórica insoslayable es Rancière, quien en El desacuerdo ha dado cuerpo a la noción de "parte de los que no tienen parte" (Rancière, 1996: 25). La importancia de este concepto reside en que permite "insistir en la Idea emancipatoria igualitaria-comunista [...] en un preciso sentido marxiano" (Žižek, 2011b: 116). Ello no quiere decir que la designación rancièreana constituya meramente otro modo de referirse a la concepción marxista de la lucha de clases como proceso histórico fundamental: la misma no da cuenta de "un conflicto entre agentes particulares dentro de la realidad social" o de "una diferencia entre agentes" que puede ser descrita "mediante un detallado análisis", sino más bien de "un antagonismo" (Žižek, 2012a: 213-214) —y cuando hablamos de antagonismo en Žižek debemos remitirnos siempre al sentido que Ernesto Laclau y Chantal Mouffe dieron a él en Hegemonía y estrategia socialista. Como bien señala Dean, "partiendo de Badiou y Rancière [pero también de Laclau y Mouffe, agreguemos], Žižek afirma que el antagonismo entre los incluidos y los excluidos" —esto es, entre la parte de los que no tienen parte (lo pobres) y la parte de los que poseen una o directamente todas las partes (los ricos) - "es el antagonismo fundamental que hoy pone en crisis al capitalismo (de allí que resulte tan crucial para la idea del comunismo)" (Dean, 2012: 105).

Actuar como comunista en la actualidad sigue suponiendo intervenir en lo Real del antagonismo determinante del capitalismo. Hablamos de la lucha de clases como el antagonismo que continúa siendo el principal de los antagonismos —es decir, el que sobredetermina a todos los demás antagonismos existentes, el que estructura las cadenas equivalenciales mismas de ellos- porque, de igual manera que la "mujer es no-hombre", el proletariado es "no-burguesía, lo que quiere decir no-noburguesía": aquello que existe no son "dos clases, sino una —la burguesía- y su negación de la negación, una no-no-clase, una extraña clase que sólo puede triunfar aboliéndose a sí misma como clase y terminando así con todas las demás clases" (Žižek, 2012b: 785). Efectivamente, el antagonismo de la lucha de clases es el más importante a causa de que es radicalmente asimétrico: 
el objetivo del proletariado no es simplemente negar [...] a su enemigo, los capitalistas, sino negarse (abolirse) a sí mismo como clase. Esto explica por qué lidiamos aquí con un "tercer camino" (ni proletario ni capitalista) no excluido, pero asimismo con una suspensión del principio de contradicción (es el propio proletariado el que se esfuerza por autoabolirse, por terminar con su condición) (ibídem: 1010).

Reivindicando la idea de la parte de los que no tienen parte - la idea de parte-deninguna-parte del cuerpo social, la idea de órgano sin cuerpo- y la noción más amplia de antagonismo en la que de alguna manera la misma se basa, el pensador de Liubliana se opone "al tópico liberal-tolerante-multicultural de la 'apertura' ('nadie debería quedar fuera, todos los grupos minoritarios, estilos de vida, etc., deben tener cabida')" (Žižek, 2011b: 117). A su entender, hoy resulta imprescindible insistir en la existencia de "grupos sociales que, a cuenta de su falta de un lugar determinado en el orden 'privado' de la jerarquía social, representan directamente la universalidad" (ibídem: 116) —para parafrasear las conocidas palabras de Emmanuel J. Sieyès sobre el Tercer Estado, grupos sociales que no son nada pero quieren serlo todo. El concepto de parte-deninguna-parte es central para las actuales perspectivas emancipatorias puesto que, a diferencia del socialismo, el comunismo refiere a la universalidad singular -esto es, al vínculo que existe entre lo singular y lo universal más allá de lo particular. Como bien sintetiza žižek, "el entusiasmo revolucionario adecuadamente comunista está incondicionalmente enraizado en la completa solidaridad con esta 'parte de ninguna-parte' y con su posición de universalidad singular" (ibídem: 144).

De todo esto se desprende que, todavía en nuestros tiempos, la dictadura del proletariado encarna "la única opción auténtica que tenemos" — se trata, a entender del filósofo esloveno, de aquella expresión que "continúa señalando el problema crucial" (Žižek, 2011a: 422): el problema del antagonismo fundamental de la lucha de clases y la necesidad de la violencia. Vale decir, hoy se encontraría a la orden del día otorgarle una nueva oportunidad a la dictadura del proletariado en la medida en que enviste "el poder de la universalidad en el que aquellos que son la 'parte de ninguna parte' marcan la pauta" (ibídem: 423-424). En tanto evocan una parte que no tiene ninguna parte, un órgano despojado de cuerpo, un colectivo que reúne a "aquellos que carecen de un lugar determinado en la totalidad social, que están 'fuera de lugar"' (Žižek, 2012a: 136), los proletarios "carecen de las características particulares que legitimarían su lugar dentro del cuerpo social: pertenecen al conjunto de la sociedad sin pertenecer a ninguno de sus subconjuntos" (Žižek, 2011a: 424). Por todo esto, hoy más que nunca urge "desmitificar por completo el espantapájaros de la 'dictadura del proletariado': en lo que tiene de más básico, representa el momento vacilante en que la compleja red de representaciones queda en suspenso a causa de la intrusión directa de la universalidad en el ámbito político" (ibídem: 425).

Ahora bien, tengamos presente que si Žižek no abona al sentido tradicional de la lucha de clases - para él ésta representa un antagonismo, no un proceso 
histórico-, tampoco lo hace a la dictadura del proletariado de la misma manera en que podría hacerlo un marxista convencional. A su entender, la actual coyuntura nos lleva a radicalizar la noción de proletariado "hasta un nivel existencial mucho más allá de la imaginación de Marx" (Žižek, 2011b: 108). Lo que hoy necesitaríamos, por consiguiente, es "una noción más radical del sujeto proletario, un sujeto reducido al punto evanescente del cogito cartesiano" (ídem), despojado de todo contenido sustancial —al igual que la Idea del comunismo, el proletariado "en absoluto tiene contenido, consistencia sustancial": al motivar a la gente a pelear por él, "genera su propia actualización" (Žižek, 2012b: 187). Es por ello que, antes que de proletariado, Žižek prefiere hablar de "posición proletaria" — para él, la política emancipatoria del porvenir "no será producto de un agente social particular, sino de una explosiva combinación de diferentes agentes" (Žižek, 2011b: 108), que, conjuntamente, ocupen el lugar que corresponde a una posición proletaria.

La insistencia en el proletariado o en la posición proletaria por parte de Žižek desmiente la acusación, realizada por Laclau en La razón populista, de que él no propondría "ninguna teoría del sujeto emancipatorio" (Laclau, 2005: 296). A fin de cuentas, no es otro que el proletariado, la parte de los que no tienen parte en la sociedad global contemporánea, el que encarna el sujeto žižekiano - "todo acto es proletario", escribe el autor; "es sólo desde una posición 'proletaria' en la que se exime a uno de la posibilidad del discurso (en la que se ocupa el lugar de la 'parte de ninguna-parte' dentro del cuerpo social existente) que un acto puede emerger" (Žižek, 2012b: 434). En efecto, al reivindicarse como parte y obrar en consecuencia, aquellos que ocupen una posición proletaria pueden revelar las contradicciones del orden simbólico y dar cuenta de la naturaleza de lo Real que sobredetermina y distorsiona a éste —esto es, de la naturaleza del antagonismo de la lucha de clases. Ante todo, el comunismo debe ser tenido como un "acto de auto-emancipación colectiva mediante el cual un pueblo —como comunidad, sociedad civil, nación u organización internacional- se apodera de su propio destino" (Bosteels, 2013: 109).

A su manera, la política žižekiana continúa demostrando fidelidad a los objetivos emancipatorios del marxismo - mejor dicho, continúa demostrando fidelidad a aquello que fuera la meta última del materialismo histórico y la crítica de la economía política: el conocimiento de lo Real del capitalismo. Es claro que la apuesta por el proletariado como sujeto de la política radical ya no constituye una opción válida para pensadores como Badiou, Balibar, Laclau o Rancière. Puntualmente para Badiou, y esto es algo que ya hemos considerado, la desconfianza en el proletariado se relaciona con una presunta obsolescencia del abecedario del comunismo provisto por el marxismo - "las masas se dividen en clases, las clases están representadas por partidos y los partidos están dirigidos por líderes" (Žižek, 2011a: 417). Dicha obsolescencia del abecedario comunista que fuera articulado por Lenin y otros, respondería al hecho de que, en la situación presente, "las masas desorganizadas del capitalismo global" no se encontrarían "divididas al modo marxista tradicional", de manera tal que no podrían ya ser organizadas a través del "viejo partido de clase" (ídem). En En defensa de causas 
perdidas, el pensador oriundo de Liubliana efectúa tres observaciones a propósito de todo esto:

En primer lugar, la definición de comunismo es ambigua: la igualdad "dentro de la multiplicidad y diversidad de las funciones sociales". En segundo lugar, entender el antagonismo de clase como que "las masas se dividen en clases" lo reduce a una subdivisión dentro del cuerpo social e ignora que se trata de un corte que cruza todo el cuerpo social. En tercer lugar, ¿cuál es la categoría exacta de la imposibilidad de una toma revolucionaria del poder? ¿Se trata de un mero contratiempo temporal, de una señal que vivimos en una situación no revolucionaria, o es indicativa de las limitaciones del modelo de revolución del Estado-partido? Badiou opta por la segunda versión (ídem).

En suma, a diferencia de Badiou, Žižek entiende que el motor del comunismo es el antagonismo de la lucha de clases, que aún es válida la apuesta por el proletariado, que aunque se encuentre temporalmente contrariada la toma revolucionaria del poder continúa representando una opción y que, en consecuencia, la forma Partido-Estado no puede ser desechada sin más. En pocas palabras, lo que la actualidad reclamaría para sí es "romper la barrera del sonido", "aceptar el riesgo de volver a abrazar las grandes decisiones colectivas" (ibídem: 472). Para el autor esto sería tan así que hacia el final de Less Than Nothing, su magnum opus sobre Hegel y el materialismo dialéctico, reivindica la necesidad de forjar "un fuerte cuerpo capaz de tomar rápidas decisiones y realizarlas con la severidad requerida" — vale decir, la necesidad de la "tétrada pueblo-movimiento-partido-líder" (Žižek, 2012b: 998).

Hoy en día estamos asistiendo a una situación en la que los diferentes pueblos del mundo buscan cada vez más “'organizarse' directamente 'a sí mismos' en movimientos" (ibídem: 1000) —allí están las experiencias de Indignados y Occupy Wall Street. Sin embargo, lo máximo que estos movimientos han podido concebir es "un espacio igualitario para el debate donde todos los oradores son escogidos al azar y se les da el mismo (poco) tiempo para hablar" (ídem). El punto es que, a la hora de la acción, a la hora de la imposición de un nuevo orden, tales movimientos no pueden resultar más que impotentes. Es por eso que actualmente "se precisa algo como un Partido" (ídem). Para usar los términos de Rancière: ante tópicos como el de la noche en la que se habrían sumido los proletarios tras ser aleccionados por maestros profundamente ignorantes, Žižek insiste en la defensa de la necesidad del partido.

Aún en un movimiento de protesta radical, el pueblo no sabe lo que quiere, demanda un nuevo Amo que le diga qué hacer. Pero si el pueblo no lo sabe, ¿puede saberlo el Partido? ¿No nos encontramos aquí nuevamente ante el tema habitual del Partido poseyendo percepción histórica y liderando al pueblo? [...] El rol organizador del Partido no tiene nada que ver con el acceso a cierto conocimiento privilegiado: un partido no equivale a la figura lacaniana del sujeto-supuesto-saber sino a un campo abierto de conocimiento en el cual "todos los errores posibles" ocurren (Lenin) (ídem). 
Si bien no es lo único que los tiempos demandan — se requiere también del "Líder, la unidad del Partido y el pueblo" (ibídem: 1001)—, lo principal es y seguirá siendo el partido - que de acuerdo con Bosteels, podríamos definir como "la organización flexible de una fidelidad a los acontecimientos en medio de circunstancias imprevisibles" (Bosteels, 2013: 93).

La intuición de Žižek es que la "debilidad fatal" de la izquierda contemporánea es que no puede transformar la "rabia auténtica [...] en un programa mínimo concreto de cambio sociopolítico" (Žižek, 2013: 110). El comunismo -aquello que nombra la "lucha común" que debemos librar para solucionar los "problemas que tenemos en común" (ibídem: 68) - no puede realizarse solamente a través de "un carnaval de protestas masivas" (ibídem: 114): es imprescindible que lo haga a través de una "nueva forma de organización, disciplina y trabajo duro" (ibídem: 115). Por encima de todo, el comunismo significa entonces "acción colectiva, determinación y voluntad" (Dean, 2012: 195). El partido es un vehículo para todo ello mediante el cual puede insistirse en "una brecha específica de deseo" —una peculiar brecha de "deseo colectivo por la colectividad" (ibídem: 208).

El rol del partido es insistir en una división. Un partido politiza una parte. El partido comunista politiza la parte que no es una parte, afirmando la brecha constitutiva del pueblo y subjetivizándola como el deseo colectivo por la colectividad. Su tarea no es cumplir o satisfacer este deseo (un imposible), sino mantenerlo, cultivarlo (ibídem: 245).

\section{IV}

El trasfondo de la renovación del comunismo en curso es una percepción extremadamente pesimista de la coyuntura global. Todo lo que es argumentado actualmente por pensadores como Badiou o Žižek se encuentra amparado por la intuición de que "vivimos en tiempos apocalípticos", es decir, de que "el fin de los tiempos está cercano" (Žižek, 2011b: 108). Al respecto, en las primeras páginas de Viviendo en el final de los tiempos, Žižek escribe:

el sistema capitalista global está aproximándose a un apocalíptico punto cero. Sus "cuatro jinetes" están formados por la crisis ecológica, las consecuencias de la revolución biogenética, los desequilibrios dentro del propio sistema (los problemas de la propiedad intelectual; las luchas que se avecinan sobre las materias primas, los alimentos y el agua) y el explosivo crecimiento de las divisiones y exclusiones sociales (Žižek, 2012a: 8).

El punto, sin embargo, es que pese a lo terrible de la situación se presentan grandes oportunidades. Aceptar que la situación que se afronta es terminal significa que ella ya no puede ser percibida "como una amenaza, sino como la oportunidad de un nuevo comienzo" — vale decir, "el paso hacia un entusiasmo emancipatorio se produce solamente cuando la traumática verdad no solo se acepta de una forma emocionalmente distante, sino que se vive por completo" (ibídem: 10). 
Como resultado de la aceptación del punto muerto ante el que nos hallaríamos, hoy en día estarían apareciendo, cada vez con mayor asiduidad, "señales de una emergente subjetividad emancipatoria" (ídem). Ciertamente, enfrentaríamos algo terrible, una experiencia catastrófica, pero no obstante el momento sería provechoso - como dice Mao: "Hay un gran desorden bajo los cielos, la situación es excelente" (Tse-Tung, citado en: ídem). En consecuencia, nuestros tiempos se tratarían de tiempos verdaderamente interesantes.

En China (eso dicen), si realmente odias a alguien, la maldición que le lanzas es: ¡Espero que vivas tiempos interesantes! Históricamente los "tiempos interesantes" han sido periodos de tranquilidad, guerras y luchas por el poder, en los que millones de inocentes sufrieron las consecuencias. Actualmente nos estamos aproximando claramente a una nueva época de tiempos interesantes. Después de décadas del Estado de bienestar, cuando los recortes financieros se limitaban a breves periodos y estaban sostenidos por la promesa de que las cosas pronto regresarían a la normalidad, estamos entrando en un nuevo periodo en el que la crisis económica se ha convertido en permanente, simplemente en una manera de vivir (ibídem: 413).

En síntesis, lo que deberíamos hacer en estos tiempos interesantes que nos tocan en suerte es

aceptar que, en el plano de las posibilidades, nuestro futuro está perdido, que la catástrofe ocurrirá, que ése es nuestro destino, para, acto seguido, sobre el trasfondo de esta aceptación, movilizarnos, llevar a cabo el acto que cambiará el propio destino y, con ello, insertará una nueva posibilidad en el pasado [...] Debemos aceptar la catástrofe como inevitable $\mathrm{y}, \mathrm{a}$ continuación, actuar para deshacer de forma retroactiva el destino que ya está "dictado por los astros" (Žižek, 2011a: 473).

En este contexto, lo que tendríamos que poner en práctica en tanto comunistas es "una glacial determinación de pensar" (Žižek, 2011b: 22). Habría que detenerse, pensar todo radicalmente de nuevo y preguntarnos en qué clase de sociedad queremos vivir —como señala Žižek, "el comunismo comienza con el 'uso público de la razón'; con el pensamiento, es decir, con la universalidad igualitaria del pensamiento" (Žižek, 2013: 9).

No obstante, deberíamos también abstenernos de "cualquier intento de imaginar concretamente la futura sociedad comunista" (ibídem: 178) —como decía Hegel al comienzo de su filosofía del derecho, es "insensato" creer que se "puede ir más allá" del propio tiempo, "más allá de Rodas" (Hegel, 2004: 19). Es precisamente por esto que, a la hora de pensar a ésta, a la hora de proporcionar una definición de lo que podría llegar a ser una futura cultura comunista, una buena estrategia consiste en acudir al campo del arte. En definitiva, es en sitios como los del arte donde las señales del futuro suelen percibirse del modo más vívido. A propósito, en Arqueologías del futuro, Jameson indica: 
uno no puede imaginar ningún cambio fundamental de nuestra existencia social que antes no haya arrojado visiones utópicas cual sendas chispas de un cometa [...] La dinámica fundamental de cualquier política utópica (o de cualquier utopismo político) radicará siempre, por lo tanto, en la dialéctica entre la identidad y la diferencia, en la medida en la que dicha política tenga por objetivo imaginar, y a veces incluso hacer realidad, un sistema radicalmente distinto a éste (Jameson, 2009: 9).

En este sentido, resulta por demás interesante el tratamiento que el mismo Jameson lleva a cabo del cuento de Kafka Josefina la cantante, o El pueblo de los ratones. Este "macabro relato" (Jameson, 2000: 111) es sumamente significativo puesto que, además de ser la última pieza que Kafka publicó en vida — se trata, en cierto sentido, del testamento del autor, de su última palabra-, alberga lugar para una utopía sociopolítica, delinea los contornos de una sociedad comunista radicalmente igualitaria. El cuento abarca los temas del arte, el artista y la colectividad; como dice Jameson, en su relato Kafka capta maravillosamente bien "el anonimato esencial del pueblo, que no tiene ningún sentido del arte, ninguna reverencia por el artista, ni un lugar para la estética" (Jameson, 2000: 112). Josefina deja ser al pueblo de los ratones lo que de algún modo éste ya es. Ella constituye tan sólo "el elemento necesario de exterioridad que [...] permite que aparezca la inmanencia" (ídem); "el vehículo de la afirmación que la colectividad hace de sí misma" (ibídem: 113) —en suma, la devolución reflejada de la identidad colectiva de los ratones.

La actuación de Josefina es "menos un recital de canto que una asamblea popular" (Kafka, 1999: 233). La artista es tratada igualitaria e indiferentemente porque su única función es permitir que el pueblo se reúna. Cuando exige "privilegios sociales (exención del trabajo físico) como compensación por su trabajo, o incluso como reconocimiento de su distinción única y de su servicio irremplazable a la comunidad" (Jameson, 2000: 113), el pueblo rechaza drásticamente su solicitud, tratándola como una "celebridad no fetichizada" (Žižek, 2012a: 380) _-"así es como habría que tratar a los artistas en una sociedad comunista", escribe Žižek; "deben ser alabados y halagados, pero no deben recibir ningún privilegio material, como la exención del trabajo o raciones especiales de alimentos (ibídem: 381).

La utopía kafkiana es la utopía de un comunismo radicalmente igualitario donde no hay sitio para la diferencia individual — vale decir, la utopía de la indiferencia y el anonimato, la utopía de la "absoluta identidad colectiva" (Jameson, 2000: 113). La única gloria a la que puede aspirar Josefina es a la del olvido. Su destino, escribe Kafka, consiste en fundirse "en la innumerable multitud de los héroes de nuestro pueblo" —al igual que "sus hermanos", sólo puede obtener "la redención del olvido" (Kafka, 1999: 243), que en una sociedad liberada y reconciliada consigo misma jamás podría equivaler a la muerte.

De esta lectura de Kafka que propone Jameson, Žižek saca en limpio que algo como una cultura comunista debería poner en práctica "una forma descaradamente total de inmersión en el cuerpo social, una compartida 
escenificación social ritualista que traumatizaría a todos los buenos liberales por su 'totalitaria' intensidad" (Žižek, 2012a: 381). Asimismo, ella debería conllevar la apasionada pertenencia a un colectivo disciplinado a través del que la individualidad se disuelve. Finalmente, una cultura comunista debería privilegiar el "frío espacio universal del pensamiento racional" (ibídem: 384).

Queda claro entonces que las actuales indagaciones en el comunismo no se refieren a éste — tampoco a la hipotética forma de transición a él, la dictadura del proletariado- como si se tratara de "una palabra mágica", de "un signo vacío que carece de cualquier visión precisa o positiva de una nueva sociedad", de "una ritualizada muestra de pertenencia a una nueva comunidad iniciática" (ibídem: 388).

Como pone de manifiesto la interpretación del cuento de Kafka, el arte permite definir rasgos de un comunismo posible de instaurar algún día en la tierra. Lo que vale para Kafka vale por ejemplo también para las piezas de piano de Eric Satie, que de acuerdo con Žižek darían cuenta de "la forma propiamente comunista de la intimidad colectiva" (ibídem: 389). Al igual que la teoría y la política comunistas, que "trasladan nuestra atención desde los heroicos individuos al inmenso trabajo y sufrimiento de la invisible gente ordinaria", la música de Satie —la música propiamente comunista, arriesguemos - "traslada la atención del oyente desde el gran Tema a su inaudible fondo" (ibídem: 391). A entender de John Cage, Satie fue junto a Webern quien introdujo en música "la única idea realmente nueva desde Beethoven" (ibídem: 391). Es Satie quien plantea por primera vez en el contexto de la música el problema de la duración y el silencio. Satie escapa de la temporalidad y se dirige hacia el ámbito de la eternidad — se mueve, por así decirlo, desde "el desarrollo lineal temporal" hacia una "constelación atemporal" (ibídem: 392). No obstante, existe una diferencia entre Satie y lo que Cage mismo plantea en su célebre composición 4'33. Mientras que para Satie la música es parte del sonido del entorno, para Cage "los ruidos del entorno son la música" (ídem). Ésta no vendría a ser una cuestión relevante para Satie. Para Cage, en cambio, es verdaderamente indispensable — "como el comunismo" (ídem), agrega Žižek.

\section{V}

Y con esta indispensabilidad enunciada por el arte, volvemos al sitio de donde partimos y se nos plantea otra vez la cuestión de la "necesidad de reinventar el comunismo" (ibídem: 440) —vale decir, vuelve a planteársenos todo lo asociado con la hipótesis e Idea eterna de Badiou. Nuevamente y para concluir, ¿cuáles son y en qué consisten las tareas que el presente prescribe para nosotros?

Nuestra situación es [...] exactamente la contraria del clásico aprieto del siglo XX en el que la izquierda sabía lo que tenía que hacer (establecer la dictadura del proletariado, etc.), pero simplemente tenía que esperar pacientemente que se ofreciera la oportunidad. Actualmente no sabemos 
qué tenemos que hacer, pero tenemos que actuar ahora, porque las consecuencias de la inactividad podrían ser catastróficas. Tendremos que asumir el riesgo de dar pasos en el abismo de lo Nuevo en situaciones totalmente inapropiadas; tendremos que reinventar aspectos de lo Nuevo solo para mantener lo que era bueno de lo Viejo [...] En resumen, nuestros tiempos podrían caracterizarse de la misma forma que Stalin caracterizó a la bomba atómica: no aptos para aquellos con nervios débiles (ibídem: 488489).

¿Qué deberíamos hacer en momentos como los que hoy nos toca vivir, entonces? No desesperar, en principio. Habría que evitar tanto el embelesamiento melancólico, nostálgico-narcisista, como la aceptación cínico-realista.

En una de sus notas del Libro de los Pasajes, Walter Benjamin cita a André Mongold:

El pasado ha dejado de sí en los textos literarios imágenes comparables a las que la luz imprime sobre una placa sensible. Sólo el porvenir posee reveladores lo suficientemente activos como para poner de manifiesto perfectamente tales clichés. Muchas páginas de Marivaux o de Rousseau encierran un sentido misterioso, que los primeros lectores no podían descifrar plenamente (Mongold, citado en: Benjamin, 2005: 484).

Los acontecimientos emancipatorios que sacudieron al mundo en 2011 deberían ser leídos a la manera de las imágenes a las que Benjamin alude, es decir, como "señales del futuro" (Žižek, 2013: 174). En lo fundamental, dichos acontecimientos constituyen "fragmentos limitados, distorsionados (a veces incluso pervertidos) de un futuro utópico que yace durmiente en el presente, como su potencial oculto" (ídem). Sería nuestra obligación, nuestra responsabilidad, descubrir elementos que si bien se encuentran aquí, en nuestro espacio, pertenecen a otro tiempo - se trata de elementos que están out of joint, que provienen del "futuro emancipado", del "futuro de la Idea comunista" (ídem). No obstante, a la hora de dar con estos elementos no deberíamos olvidar que ellos sólo se harán completamente legibles una vez que el futuro haya llegado. De lo que se trata, por consiguiente, es de prestarse a "leer las señales provenientes del (hipotético) futuro comunista" y, al mismo tiempo, abstenerse de cerrar "la apertura radical de ese futuro" (ibídem: 175). Esto obedece a que las señales del futuro "no son constitutivas sino regulativas en el sentido kantiano"; sólo pueden ser discernidas si se asume comprometidamente una posición político-subjetiva - puesto que no hay ningún gran Otro, seguirlas implica "una apuesta existencial, en el sentido de Pascal" (ídem); la práctica de "una suerte de comunismo absconditus" (ibídem: 177).

En suma, hoy en día, luego de que la crisis finalmente estallara y de que la izquierda no consiguiera dar forma a un proyecto con el que transformar la resistencia en un programa positivo de cambio social, de lo único que podemos estar seguros es que el sistema existente no podrá reproducirse por siempre "sea lo que sea que venga después, [él] no será 'nuestro futuro"' (ibídem: 182). Lo que nos queda, por lo tanto, es aceptar esta apertura plenamente, "orientándonos 
a partir de nada más que ambiguos signos del futuro" (ídem). En efecto, no hay ninguna Historia con mayúsculas que haga el trabajo por nosotros, ningún viejo topo que zape y mine a la manera de la astucia de la razón. Como en la música, en la política el silencio debe prevalecer por sobre el diálogo - a fin de cuentas, el silencio es lo único de lo que jamás podremos ser despojados.

En cierta ocasión John Berger sugirió que las respuestas no pueden ser dadas más que por las multitudes; la cuestión es que, irónicamente, ellas no conocen los interrogantes para los que tienen (o, en todo caso, representan) las respuestas. ${ }^{11}$ Es justamente por ello que, como dice Eduardo Grüner, "la misión del pensamiento crítico" es "la de crear problemas, no la de resolverlos" (Grüner, 2002: 161) —esa tarea, de nuevo, es una batalla que sólo puede ser librada por los hombres en el campo de batallas en que la historia se pliega y despliega. Los intelectuales, por consiguiente, deben proceder ante las demandas de las masas como lo hiciera Claude Lévi-Strauss ante el tema de la prohibición del incesto esto es, no tratándolas como enigmas, sino como respuestas dadas a preguntas que aún no han sido formuladas. ${ }^{12}$ Así por lo menos lo cree Žižek, quien considera que las demandas de los pueblos "son respuestas" y que la tarea del filósofo o el crítico consiste en "proponer las preguntas a las que las mismas responden" (Žižek, 2012b: 1008) - "la situación", prosigue el autor, es como aquella del psicoanálisis, en la que el paciente conoce las respuestas (sus síntomas son tales respuestas) pero desconoce a lo que ellas responden, y el analista debe formular las preguntas. Sólo a través de un trabajo tan paciente como éste un programa emergerá" (ibídem: 1009).

Pensar no es tanto resolver problemas como formular los interrogantes adecuados. En definitiva, ello es lo que permite definir al comunismo no como una solución -la solución del enigma de la Historia, como decía Marx en los Manuscritos- sino más bien como el nombre de un problema.

\section{Referencias bibliográficas}

(2008) ANDERSON, Perry, Spectrum. De la derecha a la izquierda en el mundo de las ideas, (Tr. Cristina Peña Aldao), Akal, Madrid

(2002) BADIOU, Alain, "Prefazione all'edizione italiana", (Tr. Alberto Toscano). En Metapolitica, Cronopio, Nápoles

(2006) BADIOU, Alain, De un desastre oscuro. Sobre el fin de la verdad de Estado, (Tr. Irene Agoff), Amorrortu, Buenos Aires

\footnotetext{
11 "Las multitudes tienen respuestas a preguntas que todavía no han sido planteadas" (Berger, 2007: 317).

12 "Parece entonces existir la misma correlación entre el enigma y el incesto en pueblos separados por la historia, la geografía, el idioma y la cultura. Para poder establecer la comparación, elaboremos un modelo de enigma, expresando de la mejor manera sus propiedades constantes en las diversas mitologías y definámoslo desde este punto de vista como una pregunta que no admite respuesta. Sin encarar aquí todas las transformaciones posibles de este enunciado, contentémonos, a título de experiencia, con invertir los términos, lo que nos da una respuesta para la cual no hay pregunta" (Lévi-Strauss, 1976: 30).
} 
(2088a) BADIOU, Alain, ¿Qué representa el nombre de Sarkozy?, (Tr. Iván Ortega), Ellago Ediciones, Ponte Caldelas

(2008b) BADIOU, Alain, "La hipótesis comunista", New Left Review, 49, pp. 27-38

(2010a) BADIOU, Alain, "La idea del comunismo". En Analía Hounie (comp.), Sobre la idea del comunismo, (Tr. Alcira Bixio), Paidós, Buenos Aires, pp. 17-31

(2010b) BADIOU, Alain, "Preamble: What is Called Failure?". En The Communist Hypothesis, Verso, Londres y Nueva York, pp. 1-40

(2010) BADIOU, Alain y ŽIŽEK, Slavoj, L'idée du communisme, 2. Conférence de Berlin, 2010, Lignes, París

(2013) BAROT, Emmanuel. "Por un nuevo curso del comunismo revolucionario". Ideas de Izquierda. Revista de Política y Cultura, 1, pp. 37-40

(2005) BENJAMIN, Walter, Libro de los Pasajes, (Tr. Luis Fernández Castañeda, Isidro Herrera y Fernando Guerrero), Akal, Madrid

(2003) BENSAÏD, Daniel, Marx intempestivo. Grandezas y miserias de una aventura crítica, (Tr. Agustín del Moral Tajeda), Herramienta

(2010) BENSAÏD, Daniel, "Potencias del comunismo", VientoSur, 108, pp. 9-13

(2007) BERGER, John, "Afterword". En Andréi Platanov, Soul, New York Review of Books, Nueva York

(2010) BOSTEELS, Bruno, "La hipótesis izquierdista: el comunismo en la era del terror". En Analía Hounie (comp.), Sobre la idea del comunismo, (Tr. Alcira Bixio), Paidós, Buenos Aires, pp. 51-75

(2011) BOSTEELS, Bruno, The Actuality of Communism, Verso, Londres y Nueva York

(2013) BOSTEELS, Bruno, El marxismo en América Latina. Nuevos caminos al comunismo, Vicepresidencia del Estado Plurinacional de Bolivia, La Paz

(2012) DEAN, Jodi, The Communist Horizon, Verso, Londres y Nueva York

(2010) DOUZINAS, Costas y ŽIŽEK, Slavoj, "Introduction: The Idea of Communism". En Costas Douzinas y Slavoj Žižek (eds.), The Idea of Communism, Verso, Londres y Nueva York, pp. VII-X

(1995) FURET, François, El pasado de una ilusión. Ensayo sobre la idea comunista en el siglo XX, (Tr. Mónica Utrilla), Fondo de Cultura Económica, Madrid

(2008) GARCÍA LINERA, Álvaro, "El 'descubrimiento' del Estado". En Pablo Stefanoni, Franklin Ramírez y Maristella Svampa, Las vías de la emancipación. Conversaciones con Álvaro García Linera, Océano Sur, México

(2002) GRÜNER, Eduardo, El fin de las pequeñas historias. De los estudios culturales al retorno (imposible) de lo trágico, Paidós, Buenos Aires

(2010) HARDT, Michael, "Lo común en el comunismo". En Analía Hounie (comp.), Sobre la idea del comunismo, (Tr. Alcira Bixio), Paidós, Buenos Aires, pp. 129-144

(2004) HEGEL, Georg Wilhelm Friedrich, Principios de la filosofía del derecho, (Tr. Juan Luis Vernal, 1975), Sudamericana, Buenos Aires

(2010) HOUNIE, Analía (comp.), Sobre la idea del comunismo, (Tr. Alcira Bixio), Paidós, Buenos Aires

(2000) JAMESON, Fredric, Las semillas del tiempo, (Tr. Antonio Gómez Ramos), Trotta, Madrid

(2009) JAMESON, Fredric, Arqueologías del futuro. El deseo llamado utopía y otras aproximaciones de ciencia ficción, (Tr. Cristina Piña Aldao), Akal, Madrid

(1999), KAFKA, Franz, "Josefina la cantante, o El pueblo de los ratones". En La metamorfosis y otros relatos breves, (Tr. Miguel Salmerón), Austral, Madrid 
(2005) LACLAU, Ernesto, La razón populista, (Tr. Soledad Laclau), Fondo de Cultura Económica, Buenos Aires

(1973) LENIN, Vladimir Ilich, "Notas de un publicista". En Obras, Tomo XII (1921-1923), Progreso, Moscú, pp. 107-110

(1976) LÉVI-STRAUSS, Claude, Elogio de la antropología, (Tr. Carlos Rafael Giordano), Caldén, Buenos Aires

(2009) MARTELLI, Roger, Communistes, La ville brûle, Montreuil

(1971) MARX, Karl, Crítica del Programa de Gotha, Ediciones Compañero, Buenos Aires

(1975) MARX, Karl, "La guerra civil en Francia". En Karl Marx, Friedrich Engels y Vladimir llich Lenin, La Comuna de París, Polémica, Buenos Aires, pp. 7-76

(2003) MARX, Karl, El dieciocho Brumario de Luis Bonaparte, (Tr. Elisa Chuliá Rodrigo), Alianza, Madrid

(2004) MARX, Karl, Manuscritos económico-filosóficos de 1844, (Tr. Fernanda Aren, Silvina Rotemberg y Miguel Vedda), Colihue, Buenos Aires

(1985) MARX, Karl y ENGELS, Friedrich, La ideología alemana. Crítica de la novísima filosofía alemana en las personas de sus representantes Feuerbach, B. Bauer y Stirner, y del socialismo alemán en las de sus diferentes profetas, (Tr. Wenceslao Roces), Pueblos Unidos, Buenos Aires

(2004) MARX, Karl y ENGELS, Friedrich, Manifiesto comunista, Nuestra América, Buenos Aires

(2010) NANCY, Jean-Luc, "Comunismo, la palabra". En Analía Hounie (comp.), Sobre la idea del comunismo, (Tr. Alcira Bixio), Paidós, Buenos Aires, pp. 144-153

(2010) NEGRI, Antonio, "El comunismo: algunos pensamientos sobre el concepto y la práctica". En Analía Hounie (comp.), Sobre la idea del comunismo, (Tr. Alcira Bixio), Paidós, Buenos Aires, pp. 155-166

(1996) RANCIÈRE, Jacques, El desacuerdo. Política y filosofía, (Tr. Horacio Pons), Nueva Visión, Buenos Aires

(1976) TSE-TUNG, Mao, "Desechar las ilusiones, prepararse para la lucha". En Obras Escogidas, Ediciones en Lenguas Extranjeras, Pekín, pp. 441-448

(2010) ŽlŽEK, Slavoj, "Cómo volver a empezar... desde el principio". En Analía Hounie (comp.), Sobre la idea del comunismo, (Tr. Alcira Bixio), Paidós, Buenos Aires, pp. 231-249

(2011a) ŽıŽEK, Slavoj, En defensa de causas perdidas, (Tr. Francisco López Martín), Akal, Madrid

(2011b) ŽIŽEK, Slavoj, Primero como tragedia, después como farsa, (Tr. José María Amoroto Salido), Akal, Madrid

(2012a) ŽlŽEK, Slavoj, Viviendo en el final de los tiempos, (Tr. José María Amoroto Salido), Akal, Madrid

(2012b) ŽlŽEK, Slavoj, Less Than Nothing. Hegel and the Shadow of Dialectical Materialism, Verso, Londres y Nueva York

(2013) ŽlŽEK, Slavoj, El año que soñamos peligrosamente, (Tr. Antonio José Antón Fernández), Akal, Madrid

(2014) ŽlŽEK, Slavoj (ed.), La idea del comunismo. The New York Conference (2011), (Tr. Juan Gorostidi Mungia y Francisco López Martín), Akal, Madrid 